\title{
Quality of life, recovery and decision-making: a mixed methods study of mental health recovery in social care
}

\author{
Michael Coffey ${ }^{1}$ (D) Ben Hannigan ${ }^{2} \cdot$ Alan Meudell $^{3} \cdot$ Mari Jones $^{4} \cdot$ Julian Hunt $^{1} \cdot$ Deb Fitzsimmons $^{4}$
}

Received: 26 March 2018 / Accepted: 17 November 2018 / Published online: 23 November 2018

(c) The Author(s) 2018

\begin{abstract}
Purpose Mental health care is a complex system that includes social care organisations providing support for people with continuing needs. The relationship over time between decisional conflict, social support, quality of life and recovery outcomes across two time periods for people experiencing mental health problems in receipt of social care was investigated.

Methods This is a mixed methods study comprised of a quantitative survey at two time points using measures of decisional conflict, social support, recovery and quality of life in a random sample $(n=122)$ using social care services in Wales, UK. In addition, 16 qualitative case studies were developed from data collected from individuals, a supportive other and a care worker $(n=41)$ to investigate trajectories of care. Survey responses were statistically analysed using SPSS and case study data were thematically analysed.

Results Participants reported increasing decisional conflict and decreasing social support, recovery and quality of life over the two time points. Linear regression indicated that higher recovery scores predict better quality of life ratings and as ratings for social support decline this is associated with lower quality of life. Correlational analysis indicated that lower decisional conflict is associated with higher quality of life. Thematic analysis indicated that 'connectedness and recovery' is a product of 'navigating the system of care' and the experience of 'choice and involvement' achieved by individuals seeking help.

Conclusions These results indicate that quality of life for people experiencing mental health difficulties is positively associated with social support and recovery and negatively associated with decisional delay.
\end{abstract}

Keywords Mental health care $\cdot$ Shared decision-making $\cdot$ Quality of life $\cdot$ Mixed methods $\cdot$ Recovery

\section{Introduction}

The move from institutionalised mental health care has seen the advent of community-based provision in modern societies [1]. However, the relationship between key factors such as social support, involvement in decisions, recovery and quality of life $(\mathrm{QoL})$ has received limited attention. Recovery is defined as "regaining mental health to the maximum extent possible and achieving the best possible quality of life, lived as independently as possible" [2]. While there appears to be overlap between the concepts of recovery and quality of life, the direction of the relationship is not clearly established [3]. Enhancing social support from multiple sources (family, peers and community) may influence recovery and is a potential target for intervention [4]. Shared decision-making (SDM) as one means to achieve consensus on treatment goals [5] involves collaborative efforts to aid recovery and may reduce patient distress, improve functional status, improve satisfaction with services and achieve 
a greater sense of control [6]. Systematic review evidence indicates that control over aspects of one's life and building social connectedness are important in recovery [7]. However, collaborative and shared involvement in care is inconsistent with many service users uncertain about aspects of their care [8] and reporting high levels of decisional conflict [9]. Decisional conflict refers to uncertainty in a course of action such as making decisions related to one's care and is a potential measure of readiness for, or alternatively delaying, involvement in shared decision-making [10].

To address the knowledge gaps identified above, a mixed methods study of recovery, quality of life, social support and shared decision-making was conducted with a population of people using social care mental health services in Wales. The central premise of mixed methods is that the combination of approaches provides a better understanding of research problems than either method alone [11]. For the quantitative part of this study, it was hypothesised that involvement in decisions will lead over time to improved QoL and recovery outcomes for people with mental health problems. It was further hypothesised that there would be a positive association between recovery, involvement, size and depth of social networks and QoL. For the qualitative part of the study, participant accounts were examined for experiences of uncertainty in making decisions about care and access to social support, recovery and quality of life to develop a richer account of these experiences.

\section{Design and methods}

The project protocol has been previously published [12]. A mixed methods study was conducted using a random sample of people using social care mental health services in Wales, which consists of a survey using standardised measures over two time points with additional qualitative case study interviews. The aim was to provide a rich account of contemporary recovery-focused social care via an integrated exploratory analysis $[11,13]$. Ethics approval for this study was received from West of Scotland Research Ethics Service on 18th March 2014 (REC ref: 14/WS/0063).

The study was conducted at a time of financial upheaval and sustained reductions in the provision of mental health care due to austerity [14]. The setting was a national charitable provider of a range of local recovery-focused daytime social activities including drop-in groups, gardening groups, one-to-one support and activities such as art classes. People attending activities had prior or continuing experience of secondary mental health care for a range of enduring conditions and required opportunities to develop new skills and establish or maintain social contacts. Activities occurred in urban and rural settings across Wales.
A random sample of people using these services was drawn from existing anonymised databases of the charitable organisation for the survey. Random selection of survey participants was conducted by administrative staff at the charity. Staff were instructed to select every fourth entry on the database for inclusion in the survey; therefore, the research team had no details of potential participants thus achieving allocation concealment [15]. This simple randomisation approach complied with the requirements of the charity and meant that the team was blinded to the sampling procedure. A potential bias is that individuals in any particular region of Wales could have been proportionately under- or oversampled without the study team's knowledge.

Potential participants were sent a booklet containing the participant information sheet, four standardised survey measures detailed below and information on how to complete each. Consent was sought from participants for the research team to access National Health Service (NHS) case records for the purposes of completing a measure of case complexity. Permissions and access to these records were negotiated with NHS organisations. Researchers trained in using the measure read patient records to complete scores for case complexity.

Case study participants were purposively sampled from attendees at social care projects. Our aim was to select a sample representing the range of people engaged in recovery from mental health problems. Our inclusion criteria were adults of working age, who have been in receipt of mental health care, including recent $(<2$ years) and more established contact ( $>2$ years). Receipt of mental health included any primary, secondary, tertiary and/or social mental health services. Exclusion criteria included people identified by staff as being in current crisis and those who were in hospital.

\section{Data collection}

Data were collected in two overlapping stages which consist of a survey using standardised measures followed by a case study stage involving interviews with service users, a significant other and a nominated project worker. Data from case notes were collected following consent from survey participants.

A survey questionnaire pack was sent to participants at entry to the study (time point 1 ) and where possible, completed again 6-8 months (time point 2) later by telephone. This consisted of an information sheet on the study and the following measures:

1. Lubben Social Network Scale (LSNS) [16]—a 12-item scale measuring size, closeness and frequency of contact with friends, family and neighbours. 
2. Decision Conflict Scale [10]—a 16-item measure assessing the decision-maker's uncertainty in making a choice, modifiable factors contributing to uncertainty (lack of information, unclear values, and inadequate social support) and perceived effective decision-making.

3. The Process of Recovery Questionnaire (QPR) [17]—a 22-item scale which measures both intrapersonal and interpersonal tasks involved in recovery.

4. Manchester Short Assessment of Quality of Life Scale (Mansa) [18] - a brief operational measure of QoL across eight domains.

The Matching Resources to Care (MARC2) scale was used to measure complexity of needs. This is a multidimensional measure of mental health problems incorporating social situation, illness severity, risk and social exclusion components [19] completed using data collected from patient records by trained researchers. MARC2 scores helped to describe complexity so that results could be interpreted more broadly in relation to sample similarity (or otherwise) with other studies.

Participation in case studies involved individual qualitative one-to-one audio-recorded interviews with the person, their worker and significant others nominated by the person. Utilising data from up to three participants per case study, this aimed to build as complete a picture as possible based upon a multiple-perspective approach [20] by examining differing accounts of recovery. Interview schedules were designed in relation to issues identified in the relevant literature and precise wording and sequence of questions were agreed in consultation with a Lived Experience Advisory Panel (described below). Interview schedules (see supplementary file) covered experiences of involvement, social networks and recovery so that they matched the focus of the standardised measures; for example, 'Can you tell me about times when you feel professionals have successfully involved you in discussions about your care?' The interview schedules were similar for all participant groups with minor word changes to recognise individual roles, e.g. staff or family member.

\section{Public and patient involvement and study oversight}

This study was supported by two advisory panels. The main project advisory panel included colleagues from voluntary sector organisations, service users, and academic staff [21]. Its role was to provide advice and to act as a critical friend to support the project team. The second panel consisted of a five-member Lived Experience Advisory Panel (LEAP) recruited through the Involving People network. This provided advice related to question formulation, wording, sequencing, participant recruitment and user-related issues such as concerns about welfare. The project team included a mental health service user researcher (AM) who contributed to the study design, data collection, analysis and dissemination.

\section{Data analysis}

Each measure was scored using published guidelines. Quantitative data from the standardised measures were entered into SPSS v22. For the cross-sectional analysis of time point 1 and 2 data (6-8 months follow-up), descriptive and inferential statistics were produced, using parametric or non-parametric techniques (as appropriate, dependent on the nature and distribution of the data) to describe changes in primary and secondary outcomes at each time point. The null hypothesis at $p$ values less than 0.05 was rejected.

A linear regression was conducted to investigate the relationship between quality of life as measured by the Mansa questionnaire and the other 'Total' score variables (i.e. QPR, DCS and Lubben) at both time points (1 and 2), and the overall change between the two points. The Mansa Overall score was set as the dependent variable, with the other scores set as potential predictors.

Research interviews were transcribed verbatim with all identifiers removed. Data were managed and analysed with the aid of the software package, NVivo v10. Inductive and deductive codes were created and used to identify and link segments of data and to generate themes [22, 23]. Both within-case (i.e. single trajectory) and across-case analyses [24] were conducted to describe experiences of recovery in rich detail.

\section{Results}

A random sample of 900 people were sent survey booklets with $n=122$ agreeing to participate, giving a response rate of $13 \%$. The follow-up phase involved a sample of $n=50$. Case records for $n=73$ participants were identified for the purpose of completing the case complexity measure.

Case study recruitment achieved a sample of $n=16$ people using services plus $n=11$ significant others and $n=14$ nominated workers giving a total case study sample of $n=41$. One potential participant did not keep appointments on two occasions and was deemed to have withdrawn from the study.

More men ( $n=66$, range 20-66 years, mean 42.6 years $\mathrm{sd}=12.5)$ than women $(n=55$, range $20-76$ years, mean 46.8 years $s d=13.9$ ) participated in the survey. No statistical differences between male and female participants were found in an independent samples $t$ test (or a Mann-Whitney test in the case of the non-parametric general MANSA score). Case complexity [19] (Table 1) data indicated that concerns about risk were prominently reported in written records and 
Table 1 Main severity scores on MARC2 for $n=73$ of 122 participants

\begin{tabular}{lll}
\hline MARC2_severity_score $(n=73)$ & Mean & Std. dev \\
\hline Lives alone & 0.34 & 0.48 \\
Past or present risk of self-neglect & 0.53 & 0.50 \\
Past or present serious suicidal risk & 0.66 & 0.48 \\
Needs medication monitoring & 0.34 & 0.48 \\
Previous compulsory admissions & 0.32 & 0.47 \\
Past or present risk of violence to family & 0.18 & 0.39 \\
Past or present risk of violence to others & 0.36 & 0.48 \\
Overall severity score & 0.22 & 0.15 \\
\hline
\end{tabular}

that needs for medication monitoring and living alone contributed towards severity scores.

\section{Standardised measures}

Descriptive results for decisional conflict on DCS total scale are reported in Table 2 for both time points. Decisional conflict centred on medication and therapy for more than half the sample, fewer conflicts related to social issues such as housing. The DCS threshold for decisional delay is a score of 37.5 or higher. At time point $1,26.3 \%$ of the sample had scores below the threshold on the DCS and $37.9 \%$ had scores above the threshold indicating decisional delay. However, at time point $2,6.3 \%$ of the sample had below threshold scores on the DCS and $62.5 \%$ had above threshold scores indicating they were experiencing decisional delay.

Distributional analysis indicates that only the total score variable was normally distributed (for the first time point, the Kolmogorov-Smirnov test has a $p$ value of 0.053 , for the second time point $p>0.2$ ). Therefore, the matched-pair $t$ test was conducted for the total score, and the Wilcoxon signed rank test for the other subscores (uncertainty, informed, clarity, support and effective). The total score, and each of the subscores increased significantly over time (all $p$ values $<=0.001)$. The increase in scores for decisional conflict on the DCS indicates that participants experienced more decisional delay over time indicating difficulty in engaging in shared decision-making.

A score of 24 or less on the LSNS-R indicates isolation from social support. Social support scores on the LSNS-R suggest that participants were not socially isolated $(>24)$ (see Table 2). However, 34\% $(n=35)$ completing the measure at time point 1 were at or below the threshold for social isolation indicating some heterogeneity. The survey at time point 2 found that $42 \%(n=21)$ were below the threshold for social isolation. Distributional analysis indicates that both the total and family subscores on the Lubben Social Network Scale are normally distributed for the first and second time points ( $p>0.2$ for all). The friend subscore is not normally distributed

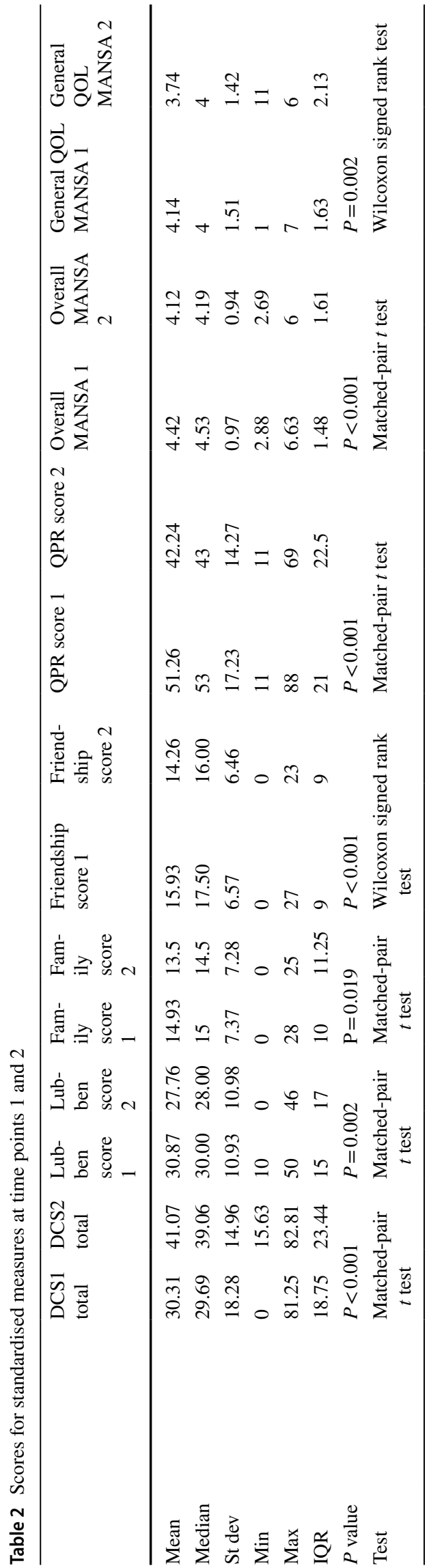


at the second time point $(p=0.012)$. Therefore, the matchedpair $t$ test was conducted for the total score and the family subscore, and the Wilcoxon signed rank test was completed for the friend subscore. The total, family subscore and friend subscore are all significant at the $95 \%$ level $(p=0.002, p=0.019$ and $p<0.001$, respectively) indicating that there was a significant decrease in LSNS-R score over time suggesting that individuals became more isolated.

Although there are no threshold points on the QPR, it was noted that scores for mental health recovery indicated $29.1 \%$ $(n=30)$ of the sample scored lower than the midway point $(<=44)$ at time point 1 suggesting recoveries that are yet to establish. At time point 2, 59.1\% $(n=26)$ scored lower than the midway point on the QPR scale. Distributional analysis (Table 2) identified that the total QPR score is normally distributed. The matched-pair $t$ test (for total score) indicated that there was a significant decrease in these scores as time progressed demonstrating diminished recovery.

\section{What are the main factors that affect initial quality of life?}

The assumptions of linear regression were satisfied with the dependent variable initial overall quality of life (MANSA overall one) and the independent variables total score variables, age and gender. A stepwise linear regression model that maximises $R^{2}$ was generated and the final model is shown below. Regression analysis was undertaken on the raw scoring variables and the standardised variables to be able to quantify the relative impact of each of the scoring variables.

\section{Raw scores}

The regression model tested is significant $(p<0.001)$ and, therefore, closer inspection of each individual independent variable was completed. Using the stepwise method, the variables are included which maximises $R^{2}$ (a measure of fit of the model) and gives the best model when all independent variables are treated equally. The final model generated in the linear regression is

$$
\begin{aligned}
\text { MANSA } 1= & 1.81+0.028 * \text { TOTAL QPR SCORE } \\
& +0.038 * \text { TOTALLUBBEN SCORE } .
\end{aligned}
$$

This model produces an $R^{2}$ value of 0.409 implying that $40.9 \%$ of the variation in the original data is accounted for by the model. This means that for a unit increase in QPR score, if all other variables are kept the same, MANSA 1 would increase by 0.028 .

\section{Standardised scores}

Variables on quality of life using the above coefficients cannot be compared for impact since they are measured on different scales. It was necessary to rerun the regression on standardised variables and then compare each of the coefficients.

The model now becomes

$$
\begin{aligned}
\text { MANSA overall }= & 4.393+0.457 * Q P R \text { score }(\text { standardised }) \\
& +0.403 * \text { LUBBENscore }(\text { standardised }) .
\end{aligned}
$$

This analysis indicates that mental health recovery (QPR score) has a bigger impact on the quality of life (MANSA score) than social support (Lubben score). Finally, by correlating quality of life (overall MANSA score) and the total scoring variables (Pearson correlation coefficients are quoted as these variables are normally distributed) all the correlation coefficients show a moderate association between the variables and quality of life (Table 3). The DCS score is negatively associated with quality of life whereas the other variables are positively associated with quality of life. This means that if DCS scores were high and results indicate increased decisional conflict, QoL scores would be expected to be lower.

\section{Case study analysis}

Anonymised details of case study participants are provided in Table 4. Analysis of qualitative data generated three broad themes which were 'navigating the systems of care', 'choices and involvement' and 'connectedness and recovery'.

\section{Theme 1: navigating the system of care}

A mental health system has been defined as all the activities whose primary purpose is to promote, restore or maintain mental health [25]. For the person needing to use it, this system can present itself as an exquisitely complex

Table 3 Pearson correlation coefficient for quality of life (MANSA score) against total scoring variables

MANSA score

(quality of life)

\begin{tabular}{ll}
\hline Total DCS score & \\
Pearson correlation & -0.459 \\
$p$ value & $P<0.000$ \\
$N$ & 79 \\
Total Lubben score & \\
Pearson correlation & 0.485 \\
$p$ value & $P<0.000$ \\
$N$ & 84 \\
Total QPR score & \\
Pearson correlation & 0.526 \\
$p$ value & $P<0.000$ \\
$N$ & 86 \\
\hline
\end{tabular}


Table 4 Anonymised details of case study participants

\begin{tabular}{|c|c|c|c|c|}
\hline $\begin{array}{l}\text { Case study } \\
\text { number }\end{array}$ & Service user & Living situation & Significant other & Case worker \\
\hline 1 & Dave & Semi-rural, independent with wife & Abigail (daughter) & Sonia (project worker) \\
\hline 2 & Derek & Urban, independent with family & - & Beverly (project worker and nurse) \\
\hline 3 & Ellen & Semi-rural, independent alone & - & - \\
\hline 4 & Frank & Urban, independent with wife & Vanessa (wife) & Bruce (project worker) \\
\hline 5 & Gwen & Urban, supported housing alone & Cameron (housing support worker) & Daphne (social worker) \\
\hline 6 & Joe & Semi-rural, independent alone & Tony (launderette owner) & Lisa (project worker) \\
\hline 7 & Lillian & Urban, independent with partner & - & Chloe (project worker) \\
\hline 8 & Melvin & Urban, supported housing with partner & - & - \\
\hline 9 & Nicola & Semi-rural, independent with child & Rita (grandmother) & Sally (CPN) \\
\hline 10 & Nina & Rural, independent with family & Jeremy (husband) & Paula (CPN) \\
\hline 11 & $\begin{array}{l}\text { Norma } \\
\text { Douglas } \\
\text { (husband) }\end{array}$ & Urban, independent with family & Marilyn (friend) & Jane (project worker) \\
\hline 12 & Patrick & Urban, independent alone & Mary (mother) & Nicholas (project worker) \\
\hline 13 & Pete & Urban, supported housing alone & Daniel (housing support worker) & Ralph (CPN) \\
\hline 14 & Rohan & Urban, independent with parents & Lorna (mother) & Penny (project worker) \\
\hline 15 & Sadie & Rural, independent with child & - & Samantha (advocacy worker) \\
\hline 16 & Tommy & Rural, independent with parents & Lynne (mother) & Rachel (project worker) \\
\hline
\end{tabular}

Key: no key worker or relative identified is signalled by inclusion of the symbol -

one. Having input in how services are delivered and decisions about one's own care is crucial and offers a form of reciprocity and a sense of epistemic justice [26].

For service users, medication was one area of contention. Decisions relating to medication were reported as imposed rather than reached by mutual agreement. For example, Sadie said,

“They've changed it quite a lot in the last 6 months and none of it has worked, and I've said to them, I don't want that medication, so I've stopped taking it. Then I get told off for stopping taking it. Then I'm like, but it was making me worse. It was making me snappy, or horrible, and I'm not that person." [Service user, Case study 15].

Sadie positioned herself as attempting to resist the use of medications which were unhelpful but felt scolded for taking an autonomous decision. Treatment led changes to personal identity, therefore, made it critical to have her voice heard. Involvement in decisions can provide the opportunity to help people engage, recover and find their way through the system of care.

Participants told us of substantial variance in care and treatment planning. Workers from social care services reported that service users were often unsure if they had a care plan and in some cases were wary of discussing these with healthcare professionals.

Lisa, a care worker for a mental health charity, said,
"You ask any service-user, have you got a care and treatment plan? First of all, they look at you and they will think, I'm not sure. Then, when you give them a bit more information, they might say, Yes, he asked me to sign that. That is not always the fault of the CPN [Community Psychiatric Nurse]. Quite often, service-users don't want to." [Worker, Case study 6].

When people were engaged in co-producing their care plan, a feeling of being involved and having ownership was reported. Navigating and accessing the system of care, however, remained difficult. For example, Abigail, who is Dave's daughter, talked about variance in cover arrangements at their local general practice, making referral back to a psychiatrist problematic,

“....That's another thing that puts my dad off. The locum can't refer to the psychiatrist." [Family member, Case study 1].

Navigating the system of care was a task made more complex as provision diversified and became less consistent.

\section{Theme 2: choices and involvement in care}

An integral element of meaningful choice is access to quality information on which to base decisions. Participants provided examples of lack of choice, of decisions imposed or care plans drafted with little input from the person themselves. 
Interviewer: With the care plan, do you feel you had more of a say in some things than other things?

Tommy: I'll tell you what, I think, no, because the care plan was very restrictive. I accept that I wasn't allowed to drink, fair enough, or allowed to use illegal drugs, again, which I didn't do. I wanted to go on holiday, they were against that. Anything that I wanted to do was stretched out and became difficult to do and it became more of a burden. So what things I wanted to do were less listened to and so forth, but with them their ideas were what we do. [Service user, Case study 16].

Tommy appeared to accept that services would be paternal at times and this was for his longer term benefit. There was evidence that service users and family members accepted the need for services to step in and take control when needed. However, a more common experience was professionals neglecting to relinquish control over relatively mundane elements of the person's life.

Participating in decisions and having those decisions respected enables a semblance of control over one's life. Getting involved in decisions was not a straightforward process as Derek intimated in the data extract below.

"As a service user-well, sometimes you're too scared to say anything, which makes it harder to know. If they gave you a leaflet to say what they were actually going to do, if they gave you like a forward planning chart, to say, "On this date we're going to try and do this with you," then I'd have a better understanding. ... So then I'd know, I'd be prepared." [Service user, Case study 2].

For many participants their experience of involvement in decisions was inconsistent and dependent largely upon individual mental health workers. Derek noted that this created uncertainty and wariness about contributing.

\section{Theme 3: connectedness and recovery}

Recovery was described as individual, achieved by the person but contextualised in relation to wider society. Different sources of social support in recovery were revealed. For example, one participant mentioned art classes for women only with each woman assigned a mentor. Participants drew contrasts with others who were constructed as less able to assert their wishes. The availability of social support was proposed by one family member, Lynne, herself a mental health service user, as a potential advocate for achieving preferred outcomes.

I fear for the people who have no family. Who have no support because I know, how can I say? They've got nobody who can stick up for them. [Family member, Case study 16].
Close family members were often the first to identify signs associated with deterioration and the onset of a crisis. They initiated contact with services and took on the role of supporter for the individual and their rights. It was often family and friends who identified and articulated progress too, thus motivating the person. Frank noted:

You don't notice your recovery, until someone else tells you ... To think, I couldn't do that last week or six months ago but I can now. I know that recovery is a long, drawn out process. It's not an overnight thing. It doesn't recover one specific problem at a time, it's different things. Different amount of time but something is happening. Slowly or whatever. But it's my family and friends. They'll tell me more about it than myself.

[Service user, Case study 4].

Frank spoke of family and friends serving an important function as an external source of reference for making judgements about progress. This contribution implicates prior knowledge of the individual before they were unwell. Shared long-term relationships may lead to more complex understandings of the identity performances of the person. Participants also report that relationships with professionals were highly valued where workers showed empathy, respect, trust and positioned the individual as a person beyond the illness. The willingness of professionals to engage the person in their own care appeared to create an atmosphere of trust and the opportunity for sharing decisions.

\section{Discussion}

This study assessed the relationship between social support, decisional conflict, recovery and quality of life in a mixed but reducing economy of provision. Accomplishing recovery in a system that is complex and organisationally fragmented is a significant challenge.

Survey data indicated that participants were reluctant to engage in decisions about their care and that this decisional conflict increased over time. These results suggest a concern about influence in decisions on treatment. It has been previously reported that forms of leverage are brought to bear in consultations between people using services and those providing them [27]. The results indicate that decisional delay is experienced by individuals meaning they were unable to participate in shared decision-making. Correlational analysis indicated that increased decisional conflict was significantly associated with lower quality of life scores. In half of these responses, the decision under question was related to medical treatment and diagnosis. Qualitative case study data indicated participants were positive about being involved in decisions. Conversely participants also provided examples related to their medical care where choice was limited, and 
decisions pressured or prescribed. Shared decision-making was mixed and consistent with findings elsewhere [9].

Case study data suggested that the role of familial relationships in supporting and establishing external social connections was important to some but for others, family was positioned as a source of their troubles. Connectedness was also an attribute associated with relationships with workers, though not in every circumstance. Stability in service provision appeared to be an important criterion for the achievement of recovery outcomes. Qualitative case study data suggesting participants unable to nominate a significant other converged with results from the quantitative measures on social support which found $35 \%$ of participants at or below the threshold for social isolation. These individuals appear reliant upon small networks and data indicating that social support was worsening over time are perhaps an indication of the delicate nature of this support. The results suggest a need for interventions to widen social participation to (re) build social capital [4].

Recovery for individuals in the study was an inconsistent experience with advances and retreats along the road towards this destination. Where recovery was scored highly there was a positive relationship with higher quality of life scores. The case studies revealed that recovery required real involvement in decisions on care and treatment and more directly in decisions about medication. Recovery and quality of life scores in the population studied were lower than reference studies [17, 28-30] suggesting this group had complex needs. These results, nevertheless, indicate new evidence that quality of life for people experiencing mental health difficulties is positively associated with social support and recovery and negatively associated with decisional delay.

The study reported here indicates the benefit of examining real-world experiences of recovery and quality of life. Individuals participating in this study were everyday users of mental health services and as such are similar to usual clinical populations. The combining of methods allowed experiences of attempting to achieve mental health recovery using standardised measures to be displayed alongside rich qualitative data.

Limitations in this study include that, to comply with local requirements, no direct access to the sampling frame was allowed. It is possible, therefore, that some under- or over-sampling of participants from specific regions of Wales occurred limiting claims of representativeness of this sample. Difficulties were encountered in locating National Health Service records for all participants and in some cases this information was incomplete. This means that the case complexity data should be considered with caution. Finally, follow-up of all participants was limited by incomplete or absent contact details; therefore, time point 2 data were recorded for less than half the original sample.

\section{Conclusions}

The results indicate that better recovery scores predict better quality of life. However, participants achieved lower scores than found in other studies and the data indicated that this was a group with complex needs. One explanation for lower recovery and quality of life scores is that this study measured recovery, social support, decisional delay and quality of life in naturally occurring settings which consist of mixed mental health service provision. As such, the findings may represent a baseline assessment of the experience of people navigating complex service provision, while living with difficult and persistent effects of mental ill health. The conclusion drawn is that mental health services appear largely resistive to shared decision-making and this may, therefore, limit opportunities to improve recovery and quality of life. The current mix of statutory and charitable provision is not achieving improved recovery outcomes and targeted service improvements that fully engage individuals and their communities in developing solutions is needed.

Acknowledgements The authors thank Ioan Humphreys and Angela Farr at SCHE for work on early analysis not used in this paper. Thanks are due to Peter Martin, Christine Wilson and colleagues at Hafal for facilitating access for data collection.

Funding This study was funded by the National Institute for Social Care and Health Research (NISCHR) in Wales (now known as Health and Care Research Wales) grant number SC-12-03.

\section{Compliance with ethical standards}

Conflict of interest On behalf of all authors, the corresponding author states that there is no conflict of interest.

Ethics statement This study has been approved by the appropriate ethics committee (West of Scotland Research Ethics Service on 18th March 2014 REC ref: 14/WS/0063) and has, therefore, been performed in accordance with the ethical standards laid down in the 1964 Declaration of Helsinki and its later amendments.

Open Access This article is distributed under the terms of the Creative Commons Attribution 4.0 International License (http://creativeco mmons.org/licenses/by/4.0/), which permits unrestricted use, distribution, and reproduction in any medium, provided you give appropriate credit to the original author(s) and the source, provide a link to the Creative Commons license, and indicate if changes were made.

\section{References}

1. Killaspy H (2007) From the asylum to community care: learning from experience. Br Med Bull 79-80(1):245-258. https://doi. org/10.1093/bmb/ld1017

2. Welsh Government (2012) Code of practice for Parts 2 and 3 of the mental health (Wales) measure 2010. Welsh Government, Cardiff 
3. Connell J, Brazier J, O'Cathain A, Lloyd-Jones M, Paisley S (2012) Quality of life of people with mental health problems: a synthesis of qualitative research. Health Quality Life Outcomes 10(1):1-16. https://doi.org/10.1186/1477-7525-10-138

4. Webber M, Reidy H, Ansari D, Stevens M, Morris D (2015) Enhancing social networks: a qualitative study of health and social care practice in UK mental health services. Health Soc Care Community 23(2):180-189. https://doi.org/10.1111/hsc.12135

5. Charles C, Gafni A, Whelan T (1997) Shared decision-making in the medical encounter: What does it mean? (or it takes at least two to tango). Soc Sci Med 44(5):681-692

6. Adams J, Drake R (2006) Shared decision-making and evidencebased practice. Community Ment Health J 42(1):87-105. https:// doi.org/10.1007/s10597-005-9005-8

7. Tew J, Ramon S, Slade M, Bird V, Melton J, Le Boutillier C (2012) Social factors and recovery from mental health difficulties: a review of the evidence. Br J Soc Work 42:443-460. https://doi. org/10.1093/bjsw/bcr076

8. Simpson A, Hannigan B, Coffey M, Barlow S, Cohen R, Jones A, Všetečková J, Faulkner A, Thornton A, Cartwright M (2016) Recovery-focused care planning and coordination in England and Wales: a cross-national mixed methods comparative case study. BMC Psychiatry 16(1):1-18. https://doi.org/10.1186/s1288 8-016-0858-x

9. Metz MJ, Veerbeek MA, van der Feltz-Cornelis CM, de Beurs E, Beekman ATF (2018) Decisional conflict in mental health care: a cross sectional study. Soc Psychiatry Psychiatric Epidemiol 53(2):161-169

10. O'Connor AM (1995) Validation of a decisional conflict scale. Med Decis Making 15(1):25-30. https://doi.org/10.1177/02729 89x9501500105

11. Creswell JW, Plano Clark PL (2011) Designing and conducting mixed methods research. SAGE Publications Ltd, London

12. Coffey M, Hannigan B, Meudell A, Hunt J, Fitzsimmons D (2016) Study protocol: a mixed methods study to assess mental health recovery, shared decision-making and quality of life (Plan4Recovery). BMC Health Serv Res. 16:392

13. O'Cathain A, Murphy E, Nicholl J (2010) Three techniques for integrating data in mixed methods studies. BMJ 341:(4587)

14. Docherty M, Thornicroft G (2015) Specialist mental health services in England in 2014: overview of funding, access and levels of care. Int J Ment Health Syst 9(1):1-8. https://doi.org/10.1186/ s13033-015-0023-9

15. Vickers AJ (2006) How to randomize. J Soc Integr Oncol 4(4):194-198

16. Lubben J, Gironda M (2004) Measuring social networks and assessing their benefits. In: Phillipson C, Allan G, Morgan DHJ (eds) Social networks and social exclusion. Sociological and Policy Perspectives Ashgate Publishing, London, pp 20-33

17. Neil ST, Kilbride M, Pitt L, Nothard S, Welford M, Sellwood W, Morrison AP (2009) The questionnaire about the process of recovery (QPR): a measurement tool developed in collaboration with service users. Psychosis 1(2):145-155. https ://doi.org/10.1080/17522430902913450

18. Priebe S, Huxley P, Knight S, Evans S (1999) Application and results of the manchester short assessment of quality of life (Mansa). Int J Soc Psychiatry 45(1):7-12. https://doi. org/10.1177/002076409904500102

19. Huxley P, Reilly S, Gater R, Robinshaw E, Harrison J, Mohamad H, Butler T, Windle B (2000) Matching resources to care: the acceptability, validity and inter-rater reliability of a new instrument to assess severe mental illness (MARC-1). Social Psychiatry Psychiatric Epidemiol 35(7):312-317

20. Rose D, Thornicroft G, Slade M (2006) Who decides what evidence is? Developing a multiple perspectives paradigm in mental health. Acta Psychiatr Scand 113(Suppl. 429):109-114

21. Slade M, Bird V, Chandler R, Fox J, Larsen J, Tew J, Leamy $M(2010)$ The contribution of advisory committees and public involvement to large studies: case study. BMC Health Serv Res 10(1):1-9. https://doi.org/10.1186/1472-6963-10-323

22. Coffey A, Atkinson P (1996) Making sense of qualitative data: complementary research strategies. Sage, London

23. Braun V, Clarke V (2006) Using thematic analysis in psychology. Qual Res Psychol 3:77-101

24. Ayres L, Kavanaugh K, Knafl KA (2003) Within-case and acrosscase approaches to qualitative data analysis. Qual Health Res 13(6):871-883. https://doi.org/10.1177/1049732303013006008

25. World Health Organization (2005) World health organization assessment instrument for mental health systems (WHO-AIMS version 2.2). World Health Organization, Geneva

26. Coffey M, Cohen R, Faulkner A, Hannigan B, Simpson A, Barlow $S$ (2017) Ordinary risks and accepted fictions: how contrasting and competing priorities work in risk assessment and mental health care planning. Health Expect 20(3):471-483. https://doi. org/10.1111/hex.12474

27. Quirk A, Chaplin R, Lelliott P, Seale C (2012) How pressure is applied in shared decisions about antipsychotic medication: a conversation analytic study of psychiatric outpatient consultations. Sociol Health Illn 34(1):95-113. https://doi.org/10.111 1/j.1467-9566.2011.01363.x

28. Slade M, Bird V, Clarke E, Le Boutillier C, McCrone P, Macpherson R, Pesola F, Wallace G, Williams J, Leamy M (2015) Supporting recovery in patients with psychosis through care by community-based adult mental health teams (REFOCUS): a multisite, cluster, randomised, controlled trial. The Lancet Psychiatry 2(6):503-514. https://doi.org/10.1016/S2215-0366(15)00086-3

29. Williams J, Leamy M, Pesola F, Bird V, Le Boutillier C, Slade M (2015) Psychometric evaluation of the questionnaire about the process of recovery (QPR). Br J Psychiatry 207(6):551-555. https ://doi.org/10.1192/bjp.bp.114.161695

30. Evans S, Huxley P, Maxwell N, Huxley K (2014) System-level change in mental health services in North Wales: An observational study using systems thinking. Int J Soc Psychiatry 60(4):337-351. https://doi.org/10.1177/0020764013489672 